\title{
Trends in In Silico Approaches to the Prediction of Biologically Active Peptides in Meat and Meat Products as an Important Factor for Preventing Food-Related Chronic Diseases
}

\author{
Paulina Kęska ${ }^{1}$ (D) Waldemar Gustaw ${ }^{2}$ and Joanna Stadnik ${ }^{1, * \mathbb{D}}$ \\ 1 Department of Animal Food Technology, Faculty of Food Science and Biotechnology, University of Life \\ Sciences in Lublin, Skromna 8, 20-704 Lublin, Poland; paulina.keska@up.lublin.pl \\ 2 Department of Plant Food Technology and Gastronomy, Faculty of Food Science and Biotechnology, \\ University of Life Sciences in Lublin, Skromna 8, 20-704 Lublin, Poland; waldemar.gustaw@up.lublin.pl \\ * Correspondence: joanna.stadnik@up.lublin.pl; Tel.: +48-81-462-33-41
}

check for updates

Citation: Kęska, P.; Gustaw, W.; Stadnik, J. Trends in In Silico Approaches to the Prediction of Biologically Active Peptides in Meat and Meat Products as an Important Factor for Preventing Food-Related Chronic Diseases. Appl. Sci. 2021, 11, 11236. https://doi.org/10.3390/ app112311236

Academic Editor: Piotr Minkiewicz

Received: 15 October 2021

Accepted: 23 November 2021

Published: 26 November 2021

Publisher's Note: MDPI stays neutral with regard to jurisdictional claims in published maps and institutional affiliations.

Copyright: (c) 2021 by the authors. Licensee MDPI, Basel, Switzerland. This article is an open access article distributed under the terms and conditions of the Creative Commons Attribution (CC BY) license (https:/ / creativecommons.org/licenses/by/ $4.0 /)$.

\begin{abstract}
The increasing awareness of modern consumers regarding the nutritional and health value of food has changed their preferences, as well their requirements, for food products, including meat and meat products. Expanding the knowledge on the impact of food on human health is currently one of the most important research areas for scientists worldwide, and it is also of interest to consumers who want to consciously compose their daily diets. New research methods, such as in silico techniques, offer solutions to these new challenges. These research methods are preferred over food evaluation, e.g., from meat, because of their advantages, such as low costs, shorter analysis times, and general availability (e.g., online databases), and are often used to design in vitro and, subsequently, in vivo tests. This review focuses on the possible use of in silico computerized methods to assess the potential of food as a source of these health-relevant biomolecules by using examples from the literature on meat and meat products. This review also provides information and important suggestions for analyzing peptides in terms of assessing their best sources, and screening those resistant to digestive factors and that show biological activity. The information provided in this review could contribute to the development of new sources of foods as biomolecules important for preventing or treating food-related chronic diseases, such as obesity, hypertension, and diabetes.
\end{abstract}

Keywords: in silico; bioinformatics; novel analytic methods; bioactive peptides

\section{Introduction}

Food-derived bioactive peptides contain 2-20 amino acids in their sequences and may show various effects in vivo [1,2]. FitzGerald and Murray [3] define bioactive peptides as molecules with hormonal or drug-like activity that (as agonists or antagonists) ultimately modulate the functions of the human body through interactions with certain receptors on target cells, leading to the induction of desired physiological responses. Bioactive peptides are inactive in the parent protein sequence until they are released by enzyme-catalyzed hydrolysis. This process occurs during fermentation and maturation in food processing. The same phenomenon occurs naturally in the digestive tract during the normal metabolism of ingested food proteins [4]. Among the different types of activities of biopeptides, their antioxidant properties, and others, are important from the point of view of etiology, for example, biopeptides that inhibit dipeptidyl peptidase IV (DPP-IV, for preventing type 2 diabetes mellitus) or angiotensin II-converting enzyme (ACE-II, for preventing hypertension). They are most often tested for their potential in preventing food-related chronic diseases, and several studies on the mechanisms of action of biologically active peptides have been reported in the literature [5-10]. These research studies indicate that food peptides have the potential to aid in the treatments of these diseases. Currently, preparations based on peptides are available on the world market, and they have been approved for 
human consumption and have a biological effect on the human body. For example, VY, obtained from sardine hydrolysate and available under the trade name, Valtyron ${ }^{\circledR}$ [11], and Katsuobushi oligopeptide (LKPNM), obtained from the bonito muscle [12], show bloodpressure-lowering effects. The hydrolysate of fish from the cod family (e.g., Stabilium 2000) or salmonids (PROTIZEN ${ }^{\circledR}$ ) have antistress and antihypertensive properties. Similar antistress and antioxidant effects are demonstrated by Fortidium Liquamen, which is based on the hydrolysates of cod fish skins [13]. The above examples show that bioactive peptides are available as supplements, in addition to a balanced diet. New trends are prompting scientists to search for peptides already present in food, including those of animal origin, in order to supply these health-promoting molecules along with (and not separately from) the daily diet.

Meat and meat products can be a source of health-promoting peptides. For example, porcine myofibrillar proteins have been shown to be precursors to peptides with 24 different activities after in silico digestion with digestive enzymes [14]. Moreover, an in silico analysis of the potential health-promoting properties of peptides from fermented beef products showed that these peptides presented activity in the cardiovascular, immune, and nervous systems, as well as other activities (a total of 17 different activities of biopeptides). Moreover, in vitro laboratory tests have repeatedly confirmed the biologically active effect of hydrolysates, extracts, or peptides isolated from raw-ripened meat products. For example, Gallego et al. [15] showed that Spanish dry-cured ham could serve as a source of naturally generated antidiabetic peptides because ham extracts are a source of peptides that can inhibit DPP IV and, thus, prevent type 2 diabetes. Montoro-García et al. [16] demonstrated, for the first time, the biological activity of peptides contained in raw-ripened pork ham on the basis of the results of in vivo studies. Their results indicate that the consumption of even small amounts of these products $(80 \mathrm{~g} /$ day for a period of 1 month) produced an in vivo effect in the form of the regulation of the carbohydrate metabolism and the cholesterol levels without increasing the amount of sodium excreted in the urine or increasing blood pressure. This is in line with the dietary recommendations and guidelines of the WHO (including the International Agency for Research on Cancer) for reducing the consumption of meat and meat products [17].

The examples cited above are promising but are mainly related to fermented or aged products. Indeed, the fermentation or natural proteolysis of proteins that occur during the few months of the aging of the meat promotes the release of biologically active peptides. Nevertheless, other meat products are also becoming the subject of increasing research that is likely to contribute to new meat products, such as cooked meat (e.g., sous vide), smoked meat, and canned meat, which will lead to the discovery of new sources of biologically active peptides and a better knowledge of these molecules. In order to reduce the difficulties associated with in vitro research (where the expenditure of time, labor, and financial resources are not proportional to the successful completion of the experiment) on biologically active peptides from various new meat products, computer testing (in silico analysis) can be performed to understand the potential of these products, and then set the direction of the research and design experiments in the laboratory.

This review presents the in silico approaches that might help in the search for new knowledge on the quantity, quality, and activity of peptides present in meat products in order to help reduce the occurrence of food-related chronic diseases. In addition, this review provides guidance for searching for peptides from meat and other food sources by using in silico tools.

\section{In Silico Approach as Part of Food Research Study}

Interventionary studies involving animals or humans, and other studies that require ethical approval, must list the authority that provided approval and the corresponding ethical approval code. The phrase "in silico" (lac. literally "in silicon," referring to the mass use of silicon in semiconductor computer circuits) is an expression used for an analysis performed on a computer or by modeling or computer simulation. This expression may be 
considered as an allusion to the Latin phrases, "in vivo", "in vitro", and "in situ", which are commonly used in biology and refer to experiments conducted on living organisms. The use of computerized methods (in silico) in research is becoming increasingly common and is considered by scientists to be as important as in vitro experimental research. Overall, knowledge obtained from an in silico analysis can be used in in vitro test design. Various fields of science use bioinformatics to better understand processes or phenomena at the molecular level (Figure 1). The approach that uses bioinformatics to assess the relationship between disease/health and food compounds is referred to as "foodomics." Foodomics uses computer software, mathematical algorithms, and statistical tools to archive, retrieve, and analyze data in the field of the biological and natural sciences. In silico analyses rely on a huge amount of data collected, including food peptides (often available online via the Internet), which are useful for empirical research and can also provide a better understanding of the structure-activity relationship of a peptide at the molecular level [18-22]. Bioinformatics tools present information on the biological and chemical properties of the molecules under study through online tools and databases. For example, databases, such as ATDB, ACEpepDB, BioPepDB, BIOPEP-UWM, EROP-Moscow, FermFooDB, SATPdb, and PepBank, and bioinformatics tools on servers (e.g., PepDraw, Peptide Property Calculator, $\mathrm{pI} / \mathrm{MW}$, ProtParam, and GRAVY Calculator) are helpful in searching information for the physicochemical properties of peptide sequences and their sources of origin (proteins), as well as for predicting their bioactivity (e.g., BIOPEP-UWM, iDPPIV-SCM, PeptideLocator, ToxinPred, and OmicTools Peptide prediction) $[10,23]$. Examples of the use of databases to search for biologically active peptides, and to evaluate their bioactivity in meat and meat products, are presented in Table 1.

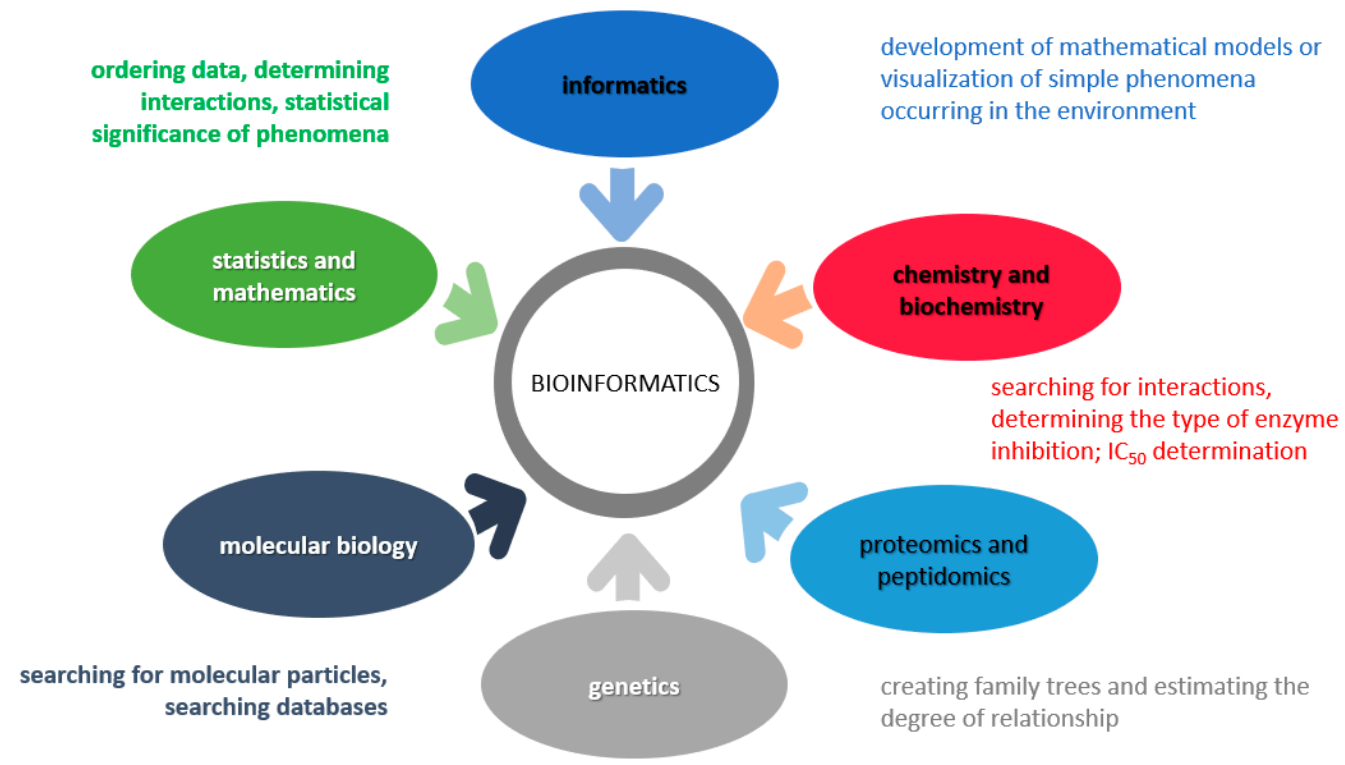

Figure 1. Application of bioinformatics in the field of science.

Computer simulations and molecular docking are also possible using bioinformatics tools. This approach is particularly helpful for assessing the complementarity of a selected peptide sequence to the active site of a molecule, most often an enzyme to inactivate it, as was the case, for example, with the peptide, ACE-I, or DPP-IV inhibitors [24-29]. By using the molecular model of the enzyme and the peptide molecule, it is possible to evaluate the possibilities of them docking each other without the need for laboratory analyses. 
Table 1. Examples of bioactive peptides from meat and meat products discovered by in silico methods.

\begin{tabular}{|c|c|c|c|c|}
\hline $\begin{array}{c}\text { Peptide Sequences and Their } \\
\text { Bioactivity }\end{array}$ & Source & $\begin{array}{l}\text { Bioinformatics Tools } \\
\text { Used in In Silico } \\
\text { Analysis }\end{array}$ & $\begin{array}{l}\text { Special Conditions of } \\
\text { Analysis }\end{array}$ & References \\
\hline $\mathrm{PPL}^{5}, \mathrm{APPH}^{5}, \mathrm{IPP}^{5}, \mathrm{PPG}^{5}$ & $\begin{array}{l}\text { Meat muscle and } \\
\text { byproducts }\end{array}$ & $\begin{array}{l}\text { BIOPEP, PeptideCutter, } \\
\text { ProtParam }\end{array}$ & $\begin{array}{l}\text { In silico hydrolysis by } \\
\text { trypsin, pepsin, papain, } \\
\text { bromelain, ficain, and } \\
\text { thermolysin }\end{array}$ & [30] \\
\hline $\mathrm{FWG}^{2}, \mathrm{MFLG}^{2}$ and SDPPLVFVG ${ }^{2}$ & Porcine liver & BIOPEP, PeptideRanker & $\begin{array}{l}\text { In silico hydrolysis by } \\
\text { papain, bromelain, } \\
\text { pepsin (pH 1.3), and } \\
\text { trypsin. }\end{array}$ & {$[31]$} \\
\hline
\end{tabular}

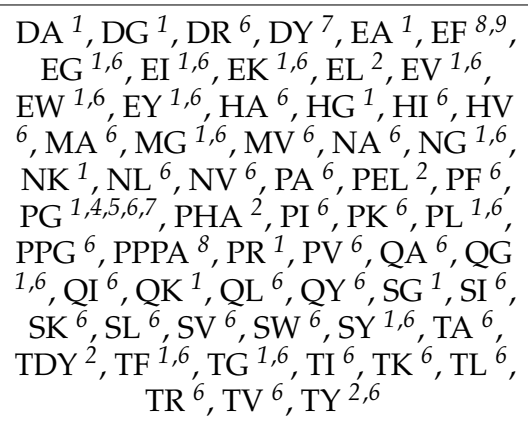

$\mathrm{AF}$ all above peptides: $3,6, \mathrm{AL}, \mathrm{AW}, \mathrm{AY}$,

DG, DR, EK, EW, EY, GF, GL, GY,

HF, HL, HR, HW, HY, IL, IR, IW, MF,

MK, ML, MR, MW, NF, NL, NR, NY,

PL, PF, PK, PW, PY, SF, SK, SL, SY,

SW, TF, TK, TL, TR, TY, QF, QL, QY,

VF, VK, VL, VR, VW, VY, VPL

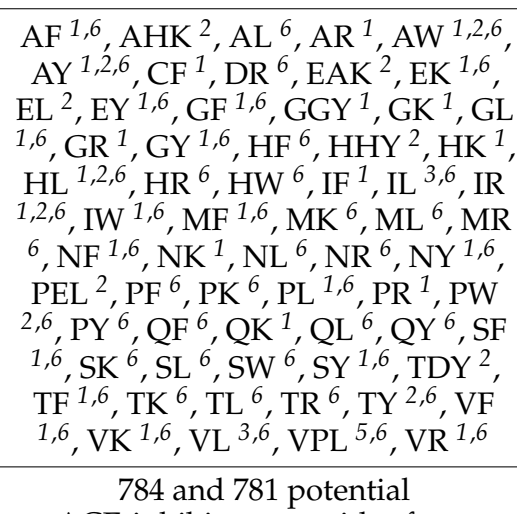

ACE-inhibitory peptides from

collagen alpha-1(I) and alpha-2(I), respectively.

130 peptides with 15 different activities

Porcine meat

BIOPEP, PepStat

In silico hydrolysis by pepsin, trypsin, and chymotrypsin
In silico hydrolysis with pepsin, trypsin, and chymotrypsin
In vivo gastric

digestion and

subsequent in silico

hydrolysis by trypsin,

chymotrypsin, and

pancreatic elastase
Porcine meat

Bovine collagen

BIOPEP, ToxinPred

In silico hydrolysis using 27 proteases

\section{In silico analysis of}

sequences after spectrometric detection

In silico analysis after

Cooked beef, pork, chicken, and turkey meat
BIOPEP, AHTPDB digestion

$>100$ bioactive peptides $1,2,6$

${ }^{1}$ inhibitor of angiotensin-II-converting enzyme (antihypertensive activity) ${ }^{2}$ antioxidative; ${ }^{3}$ glucose uptake-stimulating peptide (antidiabetic activity); ${ }^{4}$ antithrombotic; ${ }^{5}$ inhibitor of prolyl endopeptidase (impact on memory (antiamnestic), mood, eating behavior, and some neurodegenerative diseases, such as Alzheimer's disease and Parkinson's disease); ${ }^{6}$ dipeptidyl peptidase IV inhibitor (antidiabetic activity); ${ }^{7}$ regulator (regulating the stomach mucosal membrane activity or ion-flow-regulating peptide); ${ }^{8}$ inhibitor (dipeptidyl carboxypeptidase inhibitor or inhibitor of calmodulin-dependent phosphodiesterase 1 (abbrev. CaMPDE)); ${ }^{9}$ inhibitor of renin (hypotensive). ${ }^{A}$-BIOPEP (actually: BIOPEP-UWM): database of bioactive peptides; PeptideCutter: protein cleavage site prediction tool; ProtParam: tool for prediction of various physical and chemical parameters for given molecules; PEP-FOLD: online resource software used for predicting peptide structures from amino acid sequences; PepStat: calculates statistics for proteins, such as molecular weight and isoelectric point; ToxinPred: tools for predicting toxicity of peptides and proteins; AHTPDB: a comprehensive platform for analysis and presentation of antihypertensive peptides. 


\section{In Silico Studies on the Biological Activities of Meat Peptides-Theoretical Approach}

Increasing the knowledge on the impact of food on human health is currently one of the most important research areas for scientists worldwide, and it is also of interest to consumers who want to consciously compose their daily diets. This interest is based on the fact that, during metabolism, food is broken down into components that, in addition to providing nutritional value, may have biological activity. Protein is one of the most important compounds supplied to the body through the consumption of food. In addition to having structural, transport, regulatory, immune, and other functions, proteins are also a potential source of peptides with biological properties. A crucial aspect in assessing the bioactivity and bioavailability of peptides is to understand the mechanisms by which gastrointestinal enzymes catalyze the hydrolytic degradation of the proteins supplied with food. These mechanisms have been investigated by studies conducted by the European Cooperation in the Field of Scientific and Technical Research (COST), under the project name, COST INFOGEST [37]. As part of this project, research was conducted, in 34 countries globally, on the mechanisms of the digestion of food products, with a focus on the compounds released from proteins and known to have a potential effect on human health. One of the other goals of the project was to standardize the digestion models used in the research. According to the assumptions of INFOGEST, activities in this area should cover the research areas presented in Figure 2.

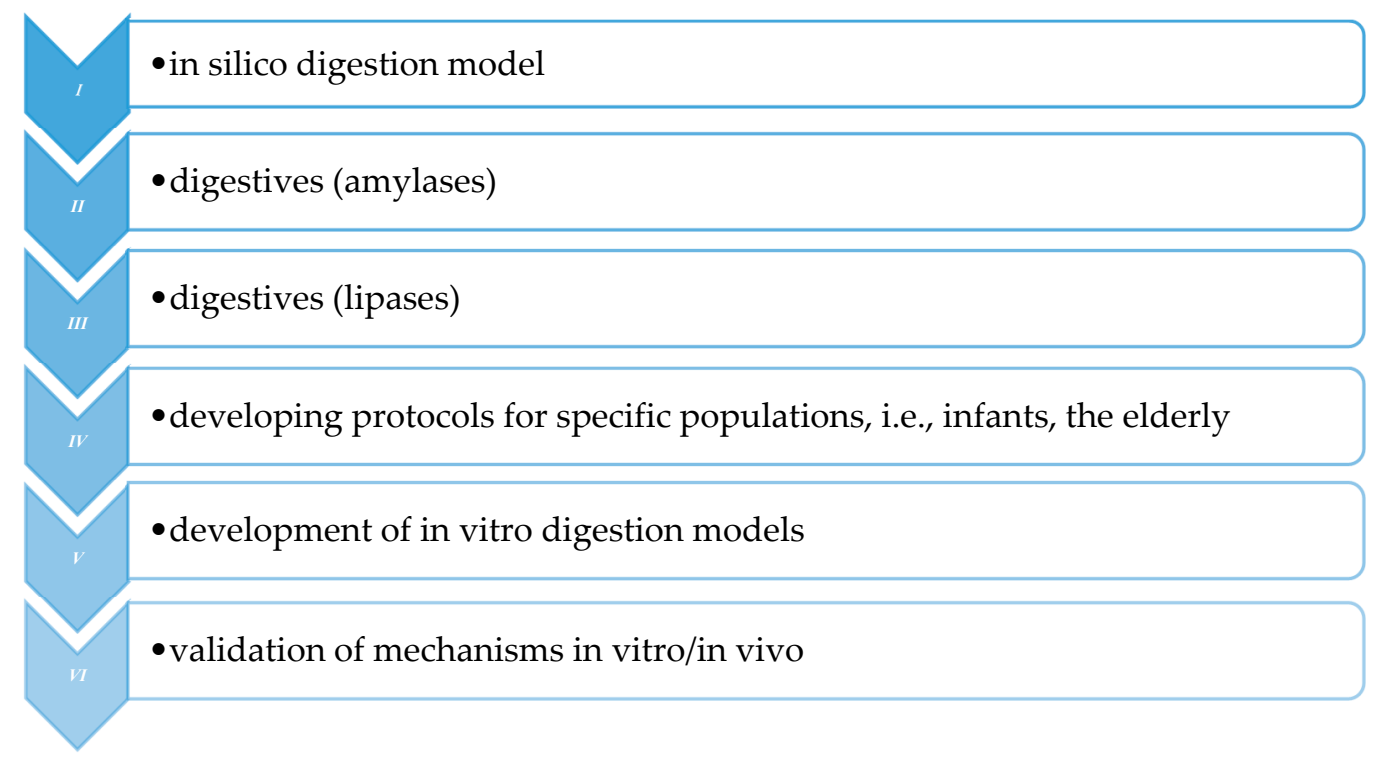

Figure 2. The main directions of research on the mechanisms of food digestion in order to release bioactive substances.

Importantly, in line with the COST INFOGEST policy of standardizing research practices, in silico digestion models were developed as Gut Map-a common reference library for in silico models related to food digestion. It is open to anyone via the Internet in order to share this work with the widest community.

The evaluation of the potential of food proteins to generate peptides is essentially based on the following steps: (I) Selecting the protein source with the highest potential for releasing an active sequence; (II) Hydrolytic peptide release (proteases/fermentation/ gastrointestinal digestion); (III) Evaluation of biological activity; and (IV) Fractionation/ isolation and characterization of peptides. To understand the unique properties of peptides released from food proteins, these steps can be accomplished by two approaches: conventional in vitro/in vivo testing, and computer-assisted techniques (in silico approach) (Figure 3). 

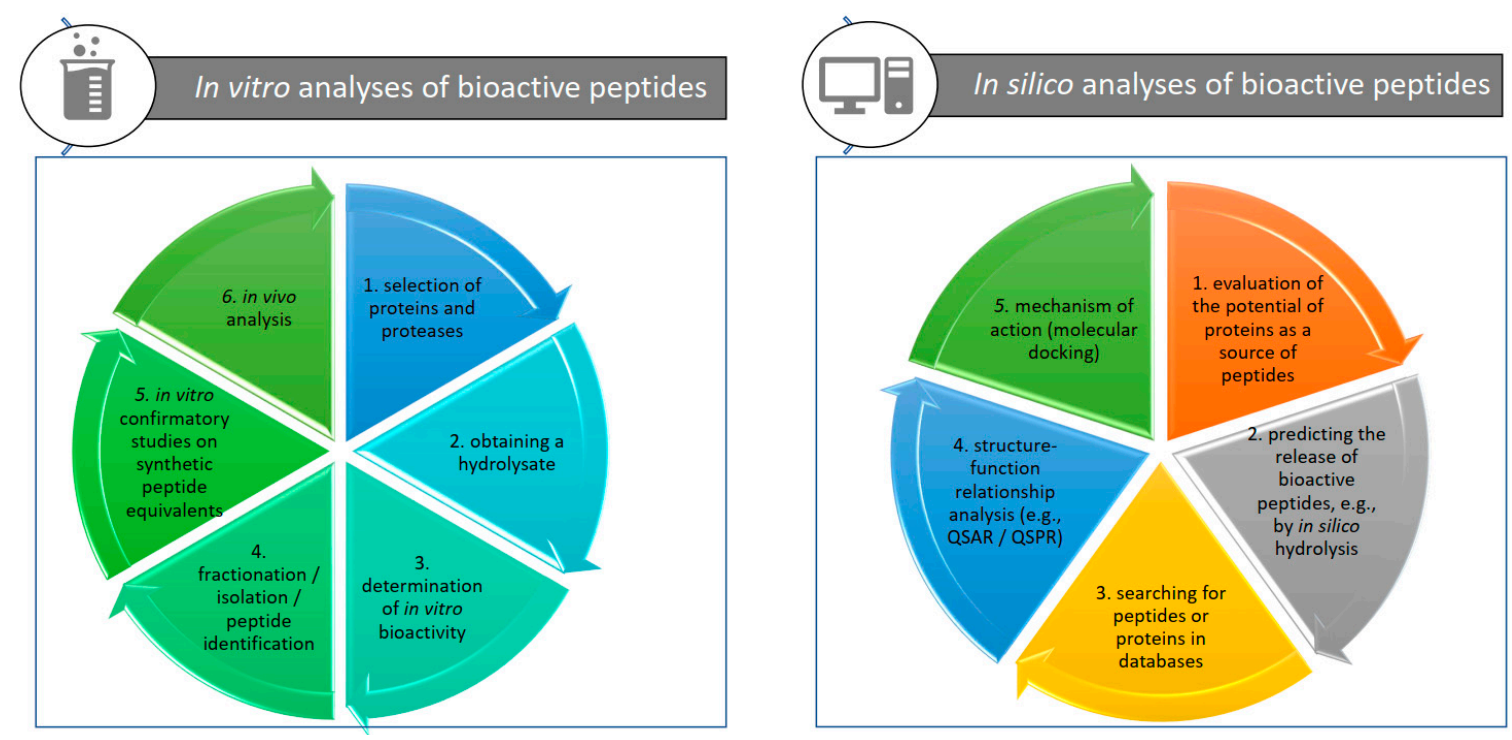

Figure 3. Tools used to identify and validate bioactive peptides from food (based on [38]).

A bioinformatics approach to identifying and analyzing bioactive food-derived peptides has been presented by Agyei et al. [39], Iwaniak et al. [40], Keeska et al. [33], Mora et al. [41], and Nongonierma et al. [42]. Research on the activity of biopeptides in food is carried out in three main directions, with the aim of developing and validating methods for obtaining and assessing their biological value: (I) Obtaining detailed knowledge on the mechanisms of generating bioactive peptides from precursor proteins; (II) Determining the biological properties of the peptides; and (III) Learning about the structures and properties of biologically active peptides that can serve as standards for designing synthetic peptide analogs or mimetics. The computational methods used in in silico research may be helpful in developing the abovementioned stages. This approach is becoming more common and has been recognized by scientists to be as important as in vitro experimental research, especially when used as part of an integrated approach. It can be divided into the following universal steps: (I) Identification of potentially bioactive peptides on the basis of the structure-function patterns; (II) Identification of proteases effective in releasing new biopeptides; (III) Experimental verification using hydrolysates or synthetic peptides; and (IV) Identification of new peptides/sources [38,39]. The research on food will contribute to gaining better knowledge on the influence of enzymatic hydrolysis with digestive enzymes and of simulated in vitro absorption on the biological activity of peptides derived from meat proteins. As shown above (Figure 2), one of the areas of activity of scientists studying the mechanisms of the digestion of food products is the creation and analysis of in silico hydrolysis models.

By using bioinformatics tools, it is also possible to estimate the antinutritional/toxic properties of food. The tools offered by the databases were used for this purpose. One of them is BIOPEP-UWM, which offers, among others, the possibility of searching for the sequence of allergenic proteins (including epitopes), while another tool is the ToxinPred website for the prediction of peptide toxicity [23,43-45]. Lafarga et al. [30] and Kęska and Stadnik [14] also used in silico tools to assess the antinutritional (toxic) properties of bovine/porcine proteins from a variety of meat muscle and byproducts. The in silico approach can also enable the evaluation of the allergenic properties of the peptides from food. The best-known animal-based food allergens are found in milk, but meat could also be a potential source. Therefore, it was assessed whether the use of acid whey (a byproduct of the dairy industry) in the preparation of mature beef would affect the allergenic properties of the product through in silico analysis (based on information available in "Allergic proteins and their epitopes" in the BIOPEP-UWM database) [35]. Within the sequence of the analyzed peptides, the epitopes (i.e., the part of the macromolecule recognized by the immune system, which forms $2 \%$ of all analyzed peptides), with a common LEKFDK 
sequence, responsible for potential allergic reactions in consumers, were located. The authors of the study identified them as a linear epitope of the Bos d 5 allergen, which is a characteristic of the allergenic bovine protein (Bos taurus) beta-lactoglobulin, gene A. The presence of this epitope was confirmed only in bovine myoglobin. Moreover, the authors of the study indicate that the use of whey did not adversely affect the allergenic properties of the fermented beef product [35]. Among all, the results of their study indicate that this type of food product is a potentially good source of bioactive compounds and is important for reducing the effects of noninfectious diseases, mainly because of the high content of DPP-IV and ACE-I inhibitors, as well as antioxidants. The in silico characterization of the allergenicity of proteins from foods, including meat sources, was also carried out by Chakraborty et al. [46]. The authors indicate that Bos taurus meat is mostly responsible for triggering allergenicity. The meat of Gallus gallus (poultry) was, however, found to be free from allergenic factors [46]. In addition to bioactivity, Lafarga et al. [47] also assessed the allergenicity and toxicity of papain hydrolysates (previously identified as the best enzymes for the production of biologically active peptides in an in silico analysis [30]) from bovine blood globulins. It was shown that the hydrolysates were not toxic but, rather, contained potential allergenic peptides.

\section{In Silico Studies on the Biological Activities of Meat Peptides-Practical Approach}

As noted by Agyei et al. [48], Udenigwe [49], and Saavedra et al. [50], by performing in vitro analyses of proteins and peptides, precise information can be obtained on both the quantities and qualities of peptides, the presence of which can be expected in a specific protein. Although it is possible to separate the protein fractions, the in vitro isolation of a single protein from muscle tissue is still problematic. Thus, the possibilities of obtaining detailed information on the potential of specific proteins as precursors of biologically active peptides by classical analyses are limited. Moreover, the search for bioactive molecules in laboratory tests is often based on the "trial-and-error" method, which, in turn, may lead to a loss of control over their biological activity, or damage to their chemical structure. An alternative is in silico analysis, especially in the first stage of designing the analytical process. The in silico procedure for the prediction and identification of bioactive peptides from meat and meat products was used by Bleakley et al. [51], Dellafiora et al. [52], Lafarga et al. [30,53], Minkiewicz et al. [54], and Mora et al. [55]. This approach enables the prediction of the types and properties of peptides that can be derived from a specific protein for selected meat proteins [55].

In silico analyses may involve many areas of the biopeptide search (Figure 4). Most often, they are conducted in two stages. First, the potential of intact (as whole particles) meat proteins is assessed. This procedure assumes that the presence of multiple biologically active peptide sequences in a protein molecule increases the likelihood of their release during enzymatic hydrolysis (in silico or in vitro). For this purpose, the abundance of the selected protein molecules containing peptides with different specific activities is assessed. This approach was reported, among others, by Fu et al. [34] who assessed the ACE inhibitory activity of the fragments contained in two collagen fractions from the nuchal ligament of bovine carcasses. When selecting proteins for this analysis, attention should also be paid to their presence in the slaughter raw material, as well as to the availability of information on the sequence of proteins. In order to evaluate meat proteins as precursors of biologically active peptides, researchers use various databases (as listed above). According to the information summarized in Table 1, the BIOPEP-UWM database is very popular; therefore, the discussion on some practical approaches is based on this database. However, it should be noted that this is not the only database (although it is often selected) on proteins and peptides available to scientists. As an example, a new approach, though not used thus far for meat biopeptides, is the use of the AnOxPePred tool and web server [56], which uses deep learning to predict the antioxidant properties of peptides. This tool helps to predict free radical scavenging and the chelating properties of peptides from 
dietary proteins [57]. Because of this feature, the database seems to be a new and useful computational tool that can aid in the search for antioxidant peptides.

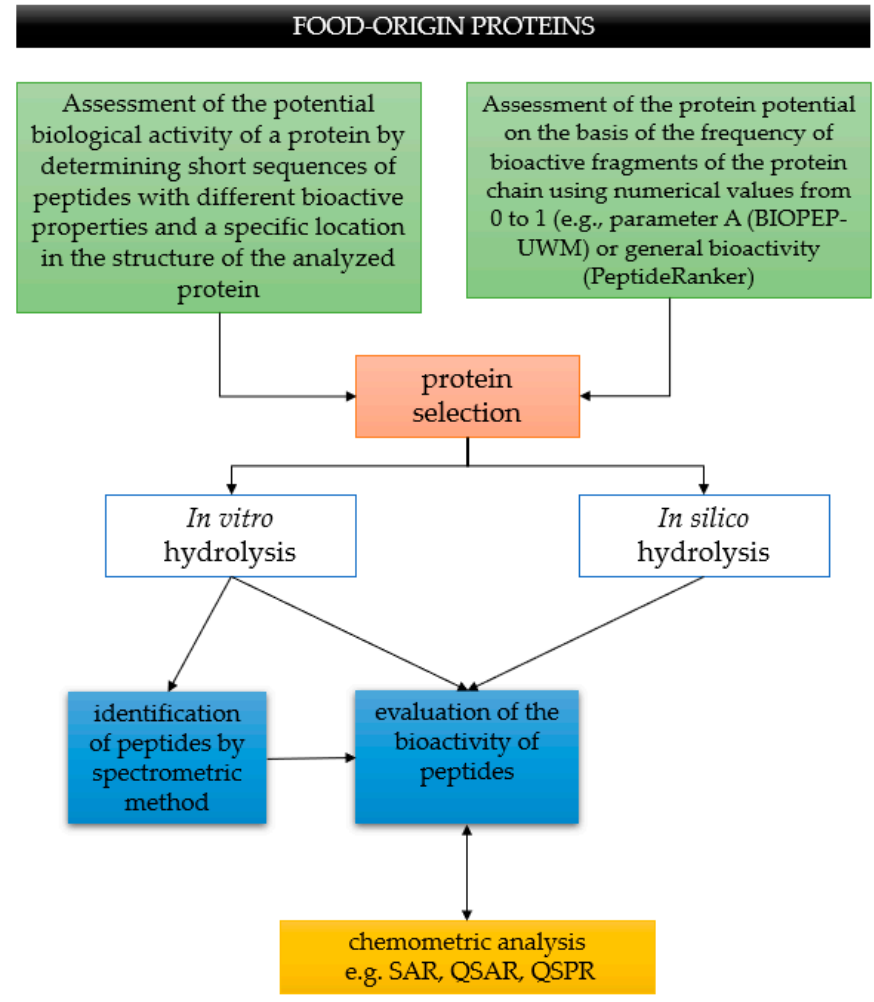

Figure 4. Workflow for assessing the biological potential of food proteins-scheme.

The value of the selected proteins as precursors of bioactive peptides can be quantified on the basis of the frequency of the occurrences of the bioactive fragments of the protein chain (e.g., parameter A; BIOPEP-UWM), and this approach was used to assess the potential bioactivity from beef [53] or pork [32]. Another example could be the Peptide Ranker, which is an online web server that uses N-to-1 neural network probability for the numerical evaluation of the bioactivity of a given sequence. This approach was used, for example, by Fu et al. [58] for evaluating the endogenous release of bioactive peptides in beef during postmortem aging times $(1,10$, and 20 days). The authors identified the peptide sequences by peptidomics (by liquid chromatography-electrospray ionization-mass spectrometry (LCESI-MS), and then subjected the identified sequences to in silico analysis (PeptideRanker and BIOPEP). It was observed that collagen peptides (with PeptideRanker bioactivity scores of 0.6-0.8) and high-score peptides (>0.8) may contribute to bioactivities [58].

The "Potential Biological Activity Profile" is another tool available in the BIOPEPUWM database and is used to discover the different bioactivities of individual protein fragments. This database provides the opportunity to discover the potential properties of the bioactive peptides in a total of 55 different activities, including those improving health (antioxidant, antihypertensive, antidiabetic, anticancer, memory-improving, and immunesystem-support properties) as well as those harmful to health (anorectic, opioid, toxic, or embryotoxic) (data for November 2021). It was previously used to predict the potential of a protein to release biologically active peptides (DPP-IV and ACE inhibitors) from muscle proteins $[22,30,54]$. Regardless of the analyzed meat protein particles, on the basis of the quoted literature sources, many different biological activities of peptides, according to their structures, were determined, which confirms the high potential of meat and meat products to modulate the physiological functions of the human body. Among them, the inhibitory activity of the enzymes, DPP-IV and ACE-I, and the antioxidant activity were most often determined (Table 1). 
Enzymatic hydrolysis is the most important method for obtaining bioactive peptides from food products and is part of the prediction of the release of bioactive peptides, as shown in Figure 2. Therefore, after determining which proteins are potentially the best sources, the next step is the hydrolytic release of the peptides from the precursor protein. For example, a total of 29 different proteases (using BIOPEP-UWM tools) were tested to evaluate the most effective enzyme for releasing peptides acting as ACE inhibitors from bovine collagen, and papain was indicated as the most effective one [34]. Lafarga et al. [30] assessed six proteases (trypsin (EC 3.4.21.4), pepsin (EC3.4.26.1), papain (EC 3.4.22.2), bromelain (EC 3.4.22.4), ficain (EC3.4.22.3), and thermolysin (EC 3.4.24.27)) for in silico hydrolysis using the programs, ExPASy PeptideCutter [59] and BIOPEP [23]. Five proteins of pork or bovine byproducts were evaluated as the substrates for use in the generation of prolyl endopeptidase inhibitory peptides [30].

The variety of enzyme preparations, and the different methods for obtaining hydrolysates (using a single enzyme or a combination thereof), offer great opportunities for the selection of the most advantageous enzyme before performing the in vitro steps. In this context, the use of in silico methods enables quick and economical design proteolysis processes and facilitates the selection of the most effective enzyme for cleaving peptide bonds. Depending on the expected results, in silico hydrolysis analysis can be performed using many different enzymes, and the only limitation is the degree of development of the database tools. However, according to the INFOGEST concept, hydrolysis that imitates the digestive processes of the human digestive system is particularly relevant. As shown in Table 1, the protein sequences were often hydrolyzed in silico with enzymes that are equivalent to human digestive proteases, namely, pepsin (EC 3.4.23.1), trypsin (EC 3.4.21.4), and chymotrypsin (EC 3.4.21.1). This integrated approach allows for the simultaneous discovery of the complete biological activity profiles of peptides released from proteins by using different proteolytic enzymes. In general, it seems that peptides released from proteins retain biological activity after the in silico hydrolysis step. Nevertheless, as shown by previous studies [14], only a part of potentially active molecules was released (or was resistant to enzymatic degradation) as a result of the action of pepsin, trypsin, and chymotrypsin. These studies were based on calculations of the frequency of bioactive peptides, which corresponds to the ratio of the number of bioactive fragments with selected activity in a dietary protein sequence (a), and the number of amino acid residues of protein (N) (parameter $\mathrm{A}=\mathrm{a} / \mathrm{N}, \mathrm{BIOPEP-UWM}$ ). These incidence values, however, consider that all bioactive sequences could be released simultaneously from the respective dietary protein and that they are equivalent in terms of their bioactive properties. However, in these in silico analyses, neither the potency of the peptides, nor the overlapping amino acid residues, were considered (the common amino acid residue may be part of different peptides, as mentioned earlier). This trend was also confirmed in an in vitro analysis, where the antiradical activity of hydrolysates after gastric digestion (compared to undigested protein extracts, expressed as the concentration of peptides that can inhibit $50 \%$ of the enzyme activity, $\mathrm{IC}_{50}$ ) of dry-cured pork loin with probiotic lactic acid bacteria (LAB) strains was reduced [60]. Interesting conclusions were drawn by Fu et al. [34], who proved that the in vitro hydrolysis of bovine collagen with papain led to the production of ACE inhibitory peptides, and the most active of them was identified as a pentapeptide (GPRGF). However, in predictive studies, this peptide was not found to be an ACE-inhibitory peptide during in silico hydrolysis by papain. According to the authors, this was mainly due to complete hydrolysis, which was not achieved by in vitro hydrolysis. This example shows that in silico analyses, despite many advantages, are not free from disadvantages, and the obtained results must be confirmed with laboratory tests, and within the broader perspective on living organisms, in order to demonstrate their impact on human health.

A different approach was presented by Sayd et al. [32], who first used an in vivo approach to evaluate the kinetics of peptide release during the hydrolysis of beef proteins in the stomachs of animals (gastric digestion steps). Subsequently, the peptides generated from the hydrolysis of the meat in the stomachs were identified and quantified 
using a spectrometric method, followed by in silico digestion mimicking the action of enzymes (intestinal digestion steps). The pool of peptides that was identified as bioactive included an ACE inhibitor, an antioxidative peptide, a glucose-uptake-stimulating peptide, an antithrombotic peptide, an antiamnestic peptide, a DPP-IV inhibitor, a regulator of the stomach mucosal membrane activity, a dipeptidyl carboxypeptidase inhibitor, and a hypotensive peptide (the list of peptides is presented in Table 1). In addition, studies have shown that certain proteins are hydrolyzed more slowly in vivo in the stomach, such as proteins involved in muscle contraction, than those noted in in vitro or in silico studies. The explanation may be that these proteins (e.g., myosin, actin, and myosin-binding protein C) form a complex (here: an actomyosin) that can reduce the availability of proteolytic enzymes to their cleavage sites located inside the protein. In silico analysis is performed on linear protein sequences (equivalent to the primary protein structure). In vivo, the structure of proteins is not so clear. There may be a quaternary form when it is a large intact protein moiety, or an intermediate form (e.g., alpha helix, beta sheet) when proteolytic enzymes are activated. It is not always possible to cleave the peptide bonds at the enzyme-specific cleavage sites within the chain. This is especially true for globular proteins, in which part of the polypeptide chain, called "the core", is hidden in the depths of the molecule and is not influenced by proteases of narrow specificities. Because of the abovementioned considerations, the stage of in silico enzymatic hydrolysis was treated as a preliminary (predictive) study, which enabled the planning of laboratory-scale studies using in vitro methods. The data obtained demonstrate the need for the further exploration and development of effective hydrolysis protocols in order to obtain the necessary information for the development of new therapeutic formulations or functional foods.

It must also be mentioned that in silico hydrolysis is also an integral part of proteomic processes, and the most frequently repeated activity in the literature is the in vitro hydrolysis of dietary proteins, and their evaluation by chromatography combined with mass spectrometry (MS). A key step in MS-based proteomics is the identification of peptides in sequence databases on the basis of their fragmentation spectra. For example, the search engine, Andromeda, uses the MaxQuant computational proteomics platform (freely available at www.maxquant.org, accessed on 1 June 2021) [61] or Mascot (usually the data are processed by Mascot Distiller and then by Mascot Search, and the results are then compared to the Uniprot database) [35,36,60]. According to Maestri et al. [62], MS is a very good method for quantifying bioactive peptides. However, although this technique has high sensitivity and accuracy, there are several problems with its use for the detection and quantification of bioactive peptides. The concentration of some peptides in food products may be below the detection limit. Another problem arises during hydrolysis. This process, occurring before MS, generates many peptides without biological activity from endogenous proteins, which may interfere with the signals from bioactive peptides and prevent the correct determination of their concentration $[63,64]$. The sequence of peptides identified by peptidomics from meat or meat products enables the accurate assessment of their bioactivity by in silico methods.

In silico analyses allow not only for the search for, and the evaluation of, the biological activity of molecules (peptides), but they also provide the opportunity to better understand the properties of the biomolecules, including their functions in the human body. The computer-assisted molecular modeling software seems to be helpful in this respect. Molecular modeling software are used as effective tools for predicting the interaction of a test compound with a target molecule. By using a theoretical simulation method (i.e., molecular docking), it is possible to predict the binding of peptides to the specific sites (e.g., receptors and active sites of enzymes) of proteins, and to quantify the binding energy by using a scoring system $[29,65]$. Generally, this approach consists of searching for the optimal (with the lowest energy) ligand-binding mode in the receptor structure (interaction of the ligand with the receptor-most often with a protein). The main assumptions of molecular docking, as well as the types of this approach and its possible application in the context of food, are presented as an example in [66]. Regarding food of animal origin, 
the molecular docking of two peptides (VGPV and GPRGF), derived from bovine collagen hydrolyzed with Alcalase ${ }^{\circledR}$ and papain, confirmed that these peptides influenced the ACE molecule and, additionally, indicated that the inhibitory mechanism of these peptides was noncompetitive [67]. Docking simulations were also carried out using ACE and different peptides from dry-cured pork ham. Molecular modeling showed that KPVAAP, KAAAATP, and KPGRP are stabilized by both hydrogen and hydrophobic interactions with at least one residue of the three pockets, which is consistent with the typical competitive inhibition model [24]. Moreover, two novel ACE inhibitory peptides (EACF and CDF) were screened from rabbit meat proteins using in silico methods. Molecular docking experiments revealed that EACF established eight H-bond interactions in the S1 and S2 pockets, and a metal-acceptor interaction with Zn 701. CDF shared four H-bond interactions in the S1 pocket of ACE [29].

Bioinformatics is closely related to chemometrics, which is a field of science that uses mathematical and statistical tools to search for useful information from multidimensional measurements. This approach is used to design, or select, the optimal experimental procedures for obtaining maximum information through data analysis, and for acquiring a knowledge of systems and the relationships between them. The described data are primarily the physicochemical parameters that characterize the tested molecules (ligands), which are reduced to their numerical forms. These are known as "descriptors". The methods used in chemometric practice to verify the rank of individual descriptors are cluster analysis, artificial neural networks, principal component analysis, the partial least squares method, etc. These methods allow for the determination of the relationship between their structures and functions by using statistical methods [38-40]. Thus, it is possible to determine which characteristics of the ligands have the most significant influence on their activity. This approach has been used to describe taste peptides [68,69] or DPP-IV inhibitory peptides [22]. In this approach, target peptides were described in a multidimensional approach by using their descriptors. Using computational methods, a mathematical model was developed for them by combining the structural features (peptide descriptors as independent variables) with the biological activity (as the dependent variable).

The in silico analysis, based on the physicochemical properties of molecules (peptides) for discovering their bioactivity, is known as the SAR (the structure-activity relationship). When using chemometry to estimate the SAR, it is assumed that if the structure of a hit is known, on the basis of the data from other similar compounds, the biological effects of this match could be predicted. This is because structurally similar compounds may have similar physical and biological properties and specific mechanisms of action. SAR analysis enables the determination of which chemical groups play an important role in inducing a target effect in the body. Biological activity can also be defined quantitatively as the minimum amount (concentration) of a certain substance that causes a specific biological response (effect). This approach is used in QSAR (the quantitative structure-activity relationship) and QSPR (the quantitative structure-property relationship) analyses. QSAR/QSPR relationship models reduce the time and costs of in vitro tests and enable the rational prediction of the biological, pharmaceutical, physical, and chemical activities/properties. These models are used by experimental scientists as the first stage of their work, and they provide information about the mechanisms of action for biological activities of interest [70]. The general workflow of QSAR/QSPR modeling can be divided into the following stages: (I) Raw data collected from the literature or public databases; (II) Initial data verification and removal of irrelevant information (e.g., by principal component analysis; (III) Definition of relevant descriptors; and (IV) Model construction and evaluation of model performance. The SAR or QSAR approaches have also been used in food research to identify food-derived bioactive peptides. For example, 242 dipeptides acting as DPP-IV inhibitors (as a set of test sequences) were tested using 16 descriptors, and an SAR model was developed for these dipeptides using principal component analysis and multiple regression analysis [22]. Gu et al. [19] showed that the proteins from pork, beef, and poultry are good precursors of ACE-inhibitory peptides $\left(\mathrm{IC}_{50}<10 \mu \mathrm{M}\right)$ by using a QSAR-aided in silico approach. These 
studies used the QSAR approach with the SIMCA-P software version +11 . In this case, the selected features of the well-known and described peptides and a set of test peptides were compared using statistical models (developed on the basis of reliable datasets). The QSAR has also been successfully applied for the prediction of the absorption, distribution, metabolism, excretion, and toxicity (ADMET) properties [71]. To aid medicinal chemists in understanding the origin of the ADMET properties, Gleeson [72] proposed a set of simple and interpretable rules using a principal component analysis of simple descriptors (e.g., molecular weight, $\log \mathrm{P}$, and ionization state) [72]. The online available tools are also helpful for the ADMET assessment (e.g., ADMETLab-a web interface for the systematic ADMET evaluation of chemical compounds on the basis of a comprehensive database). In this approach, in addition to assessing the in silico bioactivity of the molecule and determining the potential for the interaction of the ligand (peptide) with the target protein, consideration should be given to the correct absorption, metabolism, excretion, and nontoxicity, while maintaining the bioactive effect.

A common feature of computerized SAR, QSPR, or QSPR modeling and ADMET prediction is the use of information algorithms developed by machine learning in the analysis. This is an important part of the growing field of big data analytics. Machine learning, using statistical methods, creates classification or prediction algorithms while providing key information on data mining projects. Machine-learning techniques include: linear discriminant analysis (LDA); k nearest neighbor (kNN); artificial neural network (ANN); probabilistic neural network (PNN); support vector machine (SVM); decision tree (DT); recursive partitioning (RP); random forest (RF); naive Bayesian (NB); multiple linear regression (MLR); partial least squares regression (PLSR); kNN regression (kNNR); carrier vector regression (SVR); random forest regression (RFR); and combined classifier approaches [73]. Idawko [74] presented the possibility of in silico toxicity prediction using machine-learning algorithms between the structures of active substances and their activities (SAR). There are also reports of machine learning methods as ADME in in silico predictive tools, for example, for the modeling of the relationship between the chemical structure of a compound and its metabolism by enzymes [73,75].

\section{Conclusions}

In silico analyses are becoming increasingly popular in food research. Despite a few inconveniences, they are used for the initial evaluation of bioactive peptides in meat and meat products. The above review could serve as a guide for new researchers for planning their research, interpreting results, and drawing conclusions based on computational methods.

Author Contributions: Conceptualization, P.K. and J.S.; methodology, P.K.; formal analysis, P.K., W.G. and J.S.; investigation, P.K.; writing-original draft preparation; P.K.; writing-review and editing P.K., W.G. and J.S.; visualization, P.K.; project administration, P.K.; funding acquisition, P.K., W.G. and J.S. All authors have read and agreed to the published version of the manuscript.

Funding: The research was funded by the National Science Centre, Poland (Research Grant No. 2018/29/N/NZ9/01965).

Institutional Review Board Statement: Not applicable.

Informed Consent Statement: Not applicable.

Data Availability Statement: Data available on request from the authors.

Conflicts of Interest: The authors declare no conflict of interest.

\section{References}

1. Bhat, Z.F.; Kumar, S.; Bhat, H.F. Bioactive peptides of animal origin: A review. J. Food Sci. Technol. 2015, 52, 5377-5392. [CrossRef]

2. Ryan, J.T.; Ross, R.P.; Bolton, D.; Fitzgerald, G.F.; Stanton, C. Bioactive peptides from muscle sources: Meat and fish. Nutrients 2011, 3, 765-791. [CrossRef]

3. FitzGerald, R.J.; Murray, B.A. Bioactive peptides and lactic fermentations. Int. J. Dairy Technol. 2006, 59, 118-125. [CrossRef]

4. Udenigwe, C.C.; Howard, A. Meat proteome as source of functional biopeptides. Food Res. Int. 2013, 54, 1021-1032. [CrossRef] 
5. Cicero, A.F.G.; Fogacci, F.; Colletti, A. Potential role of bioactive peptides in prevention and treatment of chronic diseases: A narrative review. Br. J. Pharmacol. 2017, 174, 1378-1394. [CrossRef]

6. Admassu, H.; Gasmalla, M.A.A.; Yang, R.; Zhao, W. Bioactive Peptides Derived from Seaweed Protein and Their Health Benefits: Antihypertensive, Antioxidant, and Antidiabetic Properties. J. Food Sci. 2017, 83, 6-16. [CrossRef]

7. Li, S.; Liu, L.; He, G.; Wu, J. Molecular targets and mechanisms of bioactive peptides against metabolic syndromes. Food Funct. 2017, 9, 42-52. [CrossRef]

8. Lammi, C.; Aiello, G.; Boschin, G.; Arnoldi, A. Multifunctional peptides for the prevention of cardiovascular disease: A new concept in the area of bioactive food-derived peptides. J. Funct. Foods 2019, 55, 135-145. [CrossRef]

9. Mada, S.B.; Ugwu, C.P.; Abarshi, M.M. Health Promoting Effects of Food-Derived Bioactive Peptides: A Review. Int. J. Pept. Res. Ther. 2019, 26, 831-848. [CrossRef]

10. Kang, N.J.; Jin, H.S.; Lee, S.E.; Kim, H.J.; Koh, H.; Lee, D.W. New approaches towards the discovery and evaluation of bioactive peptides from natural resources. Crit. Rev. Environ. Sci. Technol. 2020, 50, 72-103. [CrossRef]

11. EFSA Panel on Dietetic Products, Nutrition and Allergies (NDA). Scientific Opinion on the safety of 'sardine Peptide Product'. EFSA J. 2010, 8, 1684. [CrossRef]

12. Fujita, H.; Yamagami, T.; Ohshima, K. Effects of an ACE-inhibitory agent, katsuobushi oligopeptide, in the spontaneously hypertensive rat and in borderline and mildly hypertensive subjects. Nutr. Res. 2001, 21, 1149-1158. [CrossRef]

13. Guérard, F.; Decourcelle, N.; Sabourin, C.; Floch-Laizet, C.; Le Grel, L.; Le Floc'H, P.; Gourlay, F.; Le Delezir, R.; Jaouen, P.; Bourseau, P. Recent developments of marine ingredients for food and nutraceutical applications: A review. J. Sci. Halieut. Aquat. 2010, 2, 21-27.

14. Kęska, P.; Stadnik, J. Porcine myofibrillar proteins as potential precursors of bioactive peptides-An in silico study. Food Funct. 2016, 7, 2878-2885. [CrossRef] [PubMed]

15. Gallego, M.; Aristoy, M.C.; Toldrá, F. Dipeptidyl peptidase IV inhibitory peptides generated in Spanish dry-cured ham. Meat Sci. 2014, 96, 757-761. [CrossRef]

16. Montoro-García, S.; Zafrilla-Rentero, M.P.; Celdrán-de Haro, F.M.; Piñero-de Armas, J.J.; Toldrá, F.; Tejada-Portero, L.; Abellán-Alemán, J. Effects of dry-cured ham rich in bioactive peptides on cardiovascular health: A randomized controlled trial. J. Funct. Foods. 2017, 38, 160-167. [CrossRef]

17. Bouvard, V.; Loomis, D.; Guyton, K.Z.; Grosse, Y.; Ghissassi, F.E.; Benbrahim-Tallaa, L.; Guha, N.; Mattock, H.; Straif, K. Carcinogenicity of consumption of red and processed meat. Lancet Oncol. 2015, 16, 1599-1600. [CrossRef]

18. Di Stefano, E.; Oliviero, T.; Udenigwe, C.C. Functional significance and structure-activity relationship of food-derived $\alpha-$ glucosidase inhibitors. Curr. Opin. Food Sci. 2018, 20, 7-12. [CrossRef]

19. Gu, Y.; Majumder, K.; Wu, J. QSAR-aided in silico approach in evaluation of food proteins as precursors of ACE inhibitory peptides. Food Res. Int. 2011, 44, 2465-2474. [CrossRef]

20. Pripp, A.H.; Isaksson, T.; Stepaniak, L.; Sørhaug, T.; Ardö, Y. Quantitative structure activity relationship modelling of peptides and proteins as a tool in food science. Trends Food Sci. Technol. 2005, 16, 484-494. [CrossRef]

21. Wu, D.; Sun, N.; Ding, J.; Zhu, B.; Lin, S. Evaluation and structure-activity relationship analysis of antioxidant shrimp peptides. Food Funct. 2019, 10, 5605-5615. [CrossRef]

22. Kęska, P.; Stadnik, J. Structure-activity relationships study on biological activity of peptides as dipeptidyl peptidase IV inhibitors by chemometric modeling. Chem. Biol. Drug Des. 2020, 95, 291-301. [CrossRef] [PubMed]

23. BIOPEP-UWM. Available online: http://uwm.edu.pl/biochemia/index.php/pl/biopep (accessed on 1 March 2021).

24. Martínez-Sánchez, S.M.; Pérez-Sánchez, H.; Antonio Gabaldon, J.; Abellán-Alemán, J.; Montoro-García, S. Multifunctional Peptides from Spanish Dry-Cured Pork Ham: Endothelial Responses and Molecular Modeling Studies. Int. J. Mol. Sci. 2019, 20, 4204. [CrossRef] [PubMed]

25. Lin, K.; Zhang, L.W.; Han, X.; Cheng, D.Y. Novel angiotensin I-converting enzyme inhibitory peptides from protease hydrolysates of Qula casein: Quantitative structure-activity relationship modeling and molecular docking study. J. Funct. Foods 2017, 32, 266-277. [CrossRef]

26. Xu, F.; Mejia, E.G.D.; Chen, H.; Kowalski, R.; Pan, M.; He, R.; Yao, Y.; Wang, L.; Ju, X. Assessment of the DPP-IV inhibitory activity of a novel octapeptide derived from rapeseed using Caco-2 cell monolayers and molecular docking analysis. J. Food. Biochem. 2021, 44, e13406. [CrossRef] [PubMed]

27. Yang, Y.; Shi, C.Y.; Xie, J.; Dai, J.H.; He, S.L.; Tian, Y. Identification of potential dipeptidyl peptidase (DPP)-IV inhibitors among Moringa oleifera phytochemicals by virtual screening, molecular docking analysis, ADME/T-based prediction, and in vitro analyses. Molecules 2020, 25, 189. [CrossRef]

28. Gu, H.; Gao, J.; Shen, Q.; Gao, D.; Wang, Q.; Tangyu, M.; Mao, X. Dipeptidyl peptidase-IV inhibitory activity of millet protein peptides and the related mechanisms revealed by molecular docking. LWT 2021, 138, 110587. [CrossRef]

29. Chen, J.; Yu, X.; Chen, Q.; Wu, Q.; He, Q. Screening and mechanisms of novel angiotensin-I-converting enzyme inhibitory peptides from rabbit meat proteins: A combined in silico and in vitro study. Food Chem. 2022, 370, 131070. [CrossRef]

30. Lafarga, T.; O'Connor, P.; Hayes, M. In silico methods to identify meat-derived prolyl endopeptidase inhibitors. Food Chem. 2015, 175, 337-343. [CrossRef]

31. Pearman, N.A.; Ronander, E.; Smith, A.M.; Morris, G.A. The identification and characterisation of novel bioactive peptides derived from porcine liver. Curr. Res. Food Sci. 2020, 3, 314-321. [CrossRef] 
32. Sayd, T.; Dufour, C.; Chambon, C.; Buffière, C.; Remond, D.; Sante-Lhoutellier, V. Combined in vivo and in silico approaches for predicting the release of bioactive peptides from meat digestion. Food Chem. 2018, 249, 111-118. [CrossRef]

33. Kęska, P.; Stadnik, J.; Bąk, O.; Borowski, P. Meat Proteins as Dipeptidyl Peptidase IV Inhibitors and Glucose Uptake Stimulating Peptides for the Management of a Type 2 Diabetes Mellitus In Silico Study. Nutrients 2019, 11, 2537. [CrossRef]

34. Fu, Y.; Young, J.F.; Løkke, M.M.; Lametsch, R.; Aluko, R.E.; Therkildsen, M. Revalorisation of bovine collagen as a potential precursor of angiotensin I-converting enzyme (ACE) inhibitory peptides based on in silico and in vitro protein digestions. $J$. Funct. Foods 2016, 24, 196-206. [CrossRef]

35. Keska, P.; Wójciak, K.M.; Stadnik, J. Bioactive peptides from beef products fermented by acid whey-in vitro and in silico study. Sci. Agric. 2019, 76, 311-320. [CrossRef]

36. Martini, S.; Conte, A.; Tagliazucchi, D. Comparative peptidomic profile and bioactivities of cooked beef, pork, chicken and turkey meat after in vitro gastro-intestinal digestion. J. Proteom. 2019, 208, 103500. [CrossRef]

37. INFOGEST. Available online: www.cost-infogest.eu (accessed on 1 March 2021).

38. Nongonierma, A.B.; FitzGerald, R.J. Strategies for the discovery and identification of food protein-derived biologically active peptides. Trends Food Sci. Technol. 2017, 69, 289-305. [CrossRef]

39. Agyei, D.; Tsopmo, A.; Udenigwe, C.C. Bioinformatics and peptidomics approaches to the discovery and analysis of food-derived bioactive peptides. Anal. Bioanal. Chem. 2018, 410, 3463-3472. [CrossRef] [PubMed]

40. Iwaniak, A.; Minkiewicz, P.; Darewicz, M.; Protasiewicz, M.; Mogut, D. Chemometrics and cheminformatics in the analysis of biologically active peptides from food sources. J. Funct. Foods 2015, 16, 334-351. [CrossRef]

41. Mora, L.; Gallego, M.; Reig, M.; Toldrá, F. Challenges in the quantitation of naturally generated bioactive peptides in processed meats. Trends Food Sci. Technol. 2017, 69, 306-314. [CrossRef]

42. Nongonierma, A.B.; Paolella, S.; Mudgil, P.; Maqsood, S.; FitzGerald, R.J. Identification of novel dipeptidyl peptidase IV (DPP-IV) inhibitory peptides in camel milk protein hydrolysates. Food Chem. 2018, 244, 340-348. [CrossRef] [PubMed]

43. Minkiewicz, P.; Iwaniak, A.; Darewicz, M. BIOPEP-UWM database of bioactive peptides: Current opportunities. Int. J. Mol. Sci. 2019, 20, 5978. [CrossRef] [PubMed]

44. Gupta, S.; Kapoor, P.; Chaudhary, K.; Gautam, A.; Kumar, R.; Raghava, G.P. In silico approach for predicting toxicity of peptides and proteins. PLoS ONE 2013, 8, e73957. [CrossRef]

45. ToxinPred. Available online: http://crdd.osdd.net/raghava/toxinpred/ (accessed on 1 March 2021).

46. Chakraborty, S.; Foysal, S.H.; Hasan, M.N.; Khan, N. In silico characterization and comparative analysis of allergenicity of allergic proteins from different food sources. Am. J. Biochem. Biotechnol. 2015, 11, 17-24. [CrossRef]

47. Lafarga, T.; Wilm, M.; Wynne, K.; Hayes, M. Bioactive hydrolysates from bovine blood globulins: Generation, characterisation, and in silico prediction of toxicity and allergenicity. J. Funct. Foods 2016, 24, 142-155. [CrossRef]

48. Agyei, D.; Ongkudon, C.M.; Wei, C.Y.; Chan, A.S.; Danquah, M.K. Bioprocess challenges to the isolation and purification of bioactive peptides. Food Bioprod. Process. 2016, 98, 244-256. [CrossRef]

49. Udenigwe, C.C. Bioinformatics approaches, prospects and challenges of food bioactive peptide research. Trends Food Sci. Technol. 2014, 36, 137-143. [CrossRef]

50. Saavedra, L.; Hebert, E.M.; Minahk, C.; Ferranti, P. An overview of "omic" analytical methods applied in bioactive peptide studies. Food Res. Int. 2013, 54, 925-934. [CrossRef]

51. Bleakley, S.; Hayes, M.; O'Shea, N.; Gallagher, E.; Lafarga, T. Predicted release and analysis of novel ACE-I, renin, and DPP-IV inhibitory peptides from Common common Oat oat (Avena sativa) protein hydrolysates using in silico analysis. Foods 2017, 6, 108. [CrossRef] [PubMed]

52. Dellafiora, L.; Paolella, S.; Dall'Asta, C.; Dossena, A.; Cozzini, P.; Galaverna, G. Hybrid in silico/in vitro approach for the identification of angiotensin I converting enzyme inhibitory peptides from Parma dry-cured ham. J. Agric. Food Chem. 2015, 63, 6366-6375. [CrossRef]

53. Lafarga, T.; O'Connor, P.; Hayes, M. Identification of novel dipeptidyl peptidase-IV and angiotensin-I-converting enzyme inhibitory peptides from meat proteins using in silico analysis. Peptides 2014, 59, 53-62. [CrossRef]

54. Minkiewicz, P.; Dziuba, J.; Michalska, J. Bovine meat proteins as potential precursors of biologically active peptides-a computational study based on the BIOPEP database. Food Sci. Technol. Int. 2011, 17, 39-45. [CrossRef] [PubMed]

55. Mora, L.; Gallego, M.; Toldrá, F. ACEI-inhibitory peptides naturally generated in meat and meat products and their health relevance. Nutrients 2018, 10, 1259. [CrossRef]

56. AnOxPePred. Available online: http://services.bioinformatics.dtu.dk/service.php?AnOxPePred\%201.0 (accessed on 10 June 2021).

57. Olsen, T.H.; Yesiltas, B.; Marin, F.I.; Pertseva, M.; García-Moreno, P.J.; Gregersen, S.; Overgaard, M.T.; Jacobsen, C.; Lund, O.; Hansen, E.B.; et al. AnOxPePred: Using deep learning for the prediction of antioxidative properties of peptides. Sci. Rep. 2020, 10, 21471. [CrossRef] [PubMed]

58. Fu, Y.; Young, J.F.; Therkildsen, M. Bioactive peptides in beef: Endogenous generation through postmortem aging. Meat Sci. 2017, 123, 134-142. [CrossRef]

59. PeptideCutter. Available online: https://web.expasy.org/peptide_cutter/ (accessed on 1 March 2021).

60. Kęska, P.; Stadnik, J. Stability of antiradical activity of protein extracts and hydrolysates from dry-cured pork loins with probiotic strains of LAB. Nutrients 2018, 10, 521. [CrossRef] 
61. Cox, J.; Neuhauser, N.; Michalski, A.; Scheltema, R.A.; Olsen, J.V.; Mann, M. Andromeda: A peptide search engine integrated into the MaxQuant environment. J. Proteome Res. 2011, 10, 1794-1805. [CrossRef]

62. Maestri, E.; Pavlicevic, M.; Montorsi, M.; Marmiroli, N. Meta-Analysis for Correlating Structure of Bioactive Peptides in Foods of Animal Origin with Regard to Effect and Stability. Compr. Rev. Food Sci. F 2019, 18, 3-30. [CrossRef]

63. Dallas, D.C.; Guerrero, A.; Parker, E.A.; Robinson, R.C.; Gan, J.; German, J.B.; Barile, D.; Lebrilla, C.B. Current peptidomics: Applications, purification, identification, quantification, and functional analysis. Proteomics 2015, 15, 1026-1038. [CrossRef] [PubMed]

64. Tsakelidou, E.; Virgiliou, C.; Valianou, L.; Gika, H.G.; Raikos, N.; Theodoridis, G. Sample preparation strategies for the effective quantitation of hydrophilic metabolites in serum by multi-targeted HILIC-MS/MS. Metabolites 2017, 7, 13. [CrossRef]

65. Pripp, A.H.; Ardö, Y. Modelling relationship between angiotensin-(I)-converting enzyme inhibition and the bitter taste of peptides. Food Chem. 2007, 102, 880-888. [CrossRef]

66. Tao, X.; Huang, Y.; Wang, C.; Chen, F.; Yang, L.; Ling, L.; Che, Z.; Chen, X. Recent developments in molecular docking technology applied in food science: A review. Int. J. Food Sci. Technol. 2020, 55, 33-45. [CrossRef]

67. Fu, Y.; Young, J.F.; Rasmussen, M.K.; Dalsgaard, T.K.; Lametsch, R.; Aluko, R.E.; Therkildsen, M. Angiotensin I-converting enzyme-inhibitory peptides from bovine collagen: Insights into inhibitory mechanism and transepithelial transport. Food Res. Int 2016, 89, 373-381. [CrossRef]

68. Iwaniak, A.; Hrynkiewicz, M.; Bucholska, J.; Darewicz, M.; Minkiewicz, P. Structural characteristics of food protein-originating di-and tripeptides using principal component analysis. Eur. Food Res. Technol. 2018, 244, 1751-1758. [CrossRef]

69. Iwaniak, A.; Hrynkiewicz, M.; Bucholska, J.; Minkiewicz, P.; Darewicz, M. Understanding the nature of bitter-taste di- and tripeptides derived from food proteins based on chemometric analysis. J. Food Biochem. 2018, 43, e12500. [CrossRef] [PubMed]

70. Roy, K. Advances in QSAR Modeling: Applications in Pharmaceutical, Chemical, Food, Agricultural and Environmental Sciences; Springer: Cham, Switzerland, 2017; Volume 555, p. 39.

71. Khan, M.T.; Sylte, I. Predictive QSAR modeling for the successful predictions of the ADMET properties of candidate drug molecules. Curr. Drug Discov. Technol. 2007, 4, 141-149. [CrossRef] [PubMed]

72. Gleeson, M.P. Generation of a Set of Simple, Interpretable ADMET Rules of Thumb. J. Med. Chem. 2008, 51, 817-834. [CrossRef] [PubMed]

73. Tao, L.; Zhang, P.; Qin, C.; Chen, S.Y.; Zhang, C.; Chen, Z.; Zhu, F.; Yang, S.Y.; Chen, Y.Z. Recent progresses in the exploration of machine learning methods as in-silico ADME prediction tools. Adv. Drug Deliv. Rev. 2015, 86, 83-100. [CrossRef] [PubMed]

74. Idakwo, G.; Luttrell, J.; Chen, M.; Hong, H.; Zhou, Z.; Gong, P.; Zhang, C. A review on machine learning methods for in silico toxicity prediction. J. Environ. Sci. Health Part C 2018, 36, 169-191. [CrossRef]

75. Fox, T.; Kriegl, J.M. Machine learning techniques for in silico modeling of drug metabolism. Curr. Top. Med. Chem. 2006, 6, 1579-1591. [CrossRef] 